\title{
TECHNOLOGY TARGETING FOR SUSTAINABLE INTENSIFICATION OF CROP PRODUCTION IN THE DELTA REGION OF BANGLADESH
}

\author{
U. Schulthess ${ }^{a}{ }^{*}$, T.J. Krupnik ${ }^{a}$, Z.U. Ahmed ${ }^{a}$, and A.J. McDonald ${ }^{b}$ \\ a International Maize and Wheat Improvement Center (CIMMYT) - Bangladesh. House 10/B, Road 53, Gulshan-2, Dhaka, 1213, \\ Bangladesh - u.schulthess@cgiar.org \\ ${ }^{\mathrm{b}}$ International Maize and Wheat Improvement Center (CIMMYT) - South Asia Regional Office. Kathmandu, Nepal
}

\author{
Commission VI, WG VI/4
}

KEY WORDS: Sustainable intensification, cropland identification, cropland use intensity, technology targeting, risk assessment

\begin{abstract}
:
Remote sensing data are nowadays being acquired within short intervals and made available at a low cost or for free. This opens up opportunities for new remote sensing applications, such as the characterization of entire regions to identify most suitable areas for technology targeting. Increasing population growth and changing dietary habits in South Asia call for higher cereal production to ensure future food security. In the Delta area of Bangladesh, surface water is considered to be available in quantities large enough to support intensification by adding an irrigated dry season crop. Fuel-efficient, low lift axial flow pumps have shown to be suitable to carry water to fields that are within a buffer of four hundred meters of the rivers. However, information on how and where to target surface water irrigation efforts is currently lacking. We describe the opportunities and constraints encountered in developing a procedure to identify cropland for which axial flow pumps could be successfully deployed upon in a $43^{\prime} 000 \mathrm{~km} 2$ area. First, we isolated cropland and waterways using Landsat 5 and 7 scenes using image segmentation followed by classification with the random forest algorithm. Based on Landsat 7 and 8 scenes, we extracted maximum dry season enhanced vegetation index (EVI) values, which we classified into fallow, low-, and high-intensity cropland for the last three years. Last, we investigated the potential for surface water irrigation on fallow and low-intensity land by applying a cropping risk matrix to address the twin threats of soil and water salinity. Our analysis indicates that there are at least 20,000 ha of fallow land under the low-risk category, while more than 100,000 ha of low-intensity cropland can be brought into intensified production. This information will aid in technology targeting for the efficient deployment of surface water irrigation as a tool for intensification.
\end{abstract}

\section{INTRODUCTION}

\subsection{General Instructions}

Population growth projections and increases in per capita income indicate that global food requirements will continue to expand for at least four more decades before they plateau, with estimates indicating that a doubling of current staple crop production is required by 2050 (Godfray, et al., 2010, Tilman, et al., 2011).

Cereals production could be boosted by expanding the land area devoted to cropping, rather than by raising yield potential alone, though this will entail negative environmental externalities (e.g. reduced biodiversity) that should be avoided (Tilman, et al., 2011). Sustainable agricultural intensification, defined as use of sound agronomy and purposeful manipulation of ecological processes to achieve increased productivity, while minimizing land expansion and environmental degradation, has been proposed as a potential solution to these issues (Garnett, et al., 2013, Godfray, et al., 2010). A key strategy for sustainable intensification is multiple cropping, whereby at least two crops are grown per year on the same piece of land. Currently, 59, 39, 47 , and $93 \%$ of the arable land in the Indo-Gangetic Plains of Bangladesh, India, the Nepali Terai, and Pakistan are irrigated (AQUASTAT, 2013). Combined with the predominance of flooded rice as the stable crop, these figures have led to the perception that most potentially irrigable land in South Asia has already been brought into intensified production (see for example de Fraiture and Wichelns, 2010, Godfray, et al., 2010).
This situation raises the question: What agricultural environments of South Asia offer the greatest opportunities for sustainable intensification? Rather than focusing on already irrigated environments, the answer may lie in more "gamechanging" strategies to transform agricultural productivity in the remaining rainfed or partially irrigated environments where water resources are available yet land-use intensity is currently low, and where low-cost investments in surface water irrigation (SWI) could enable the move from single to double cropping. In these marginal environments, many of which lie in the underdeveloped eastern Indo-Gangetic (IGP) plain states of coastal Bangladesh and West Bengal in India, water resources development is low, and farmers typically grow only one rainfed monsoon season rice crop per year. Access to shallow groundwater is limited because upper aquifers are saline and may be restricted due to silty-clay in upper soil strata (MOA and FAO, 2012). Moreover, increases in salinity of existing aquifers can be expected as sea levels will rise in the future due to climate change. This will further threaten food security. Deep tube well expansion is similarly problematic because of the potential for salinization resulting from the draw-down of upper water layers by industrial and domestic users (Brammer, 2010), in addition to concerns arising from the natural contamination of ground water with ground rock derived arsenic (Hossain, 2006). Conversely, SWI could help to ameliorate these problems.

New low-lift SWI pumps that increase the efficiency of water delivery per unit of fuel have recently become available, which could help to lower costs and potentially encourage intensification (Santos Valle, et al., 2014). However, where 
SWI is unplanned and poorly targeted, less than optimal performance may also be expected, and social and environmental problems may arise from over-extraction and water competition. It is therefore important to approach decentralized SWI development intelligently, by identifying and targeting appropriate blocks of low-intensity cropping and fallow land for irrigation that can benefit from irrigation, and by assuring that sufficient water supply is available to sustain adequate crop growth without undesirable levels of surface water depletion. What is lacking, however, is up-to-date and precise information on how and where to target SWI efforts, while making the best use of available freshwater resources without exhausting supply or degrading water quality.

Southwestern Bangladesh hosts two of the country's three administrative divisions with the most people living below the poverty line (World Bank, 2010), with only $50 \%$ of the region's 3.4 million farming households growing more than one Aman rice crop per year (MOA and FAO, 2012). These farmers typically fallow their land during the dry season, while those that do manage a crop usually cultivate low-input and -output legumes such as grasspea (Lathyrus sativus), lentil (Lens culinaris), and mungbean (Vigna radiata) using residual soil moisture. Only $15 \%$ of the region's farmers have access to groundwater to grow dry season Boro rice (MOA and FAO, 2012).

Using the southwest of Bangladesh (Fig. 1) as a case study, this paper shows how remote sensing and GIS technologies can be used to assess land suitability for intensification through decentralized SWI in deltaic environments. Because of the regional specificity of the agronomic constraints that farmers face in southwestern Bangladesh, additional information on soil and water salinity, and dry season planting dates were also employed. The basic analytical steps described in this paper can be modified and adapted to assess similar questions pertaining to fallow or low-productivity land intensification and SWI in similar deltaic environments, thereby providing a tool for more effective technology targeting to mobilize sustainable intensification and SWI development interventions.

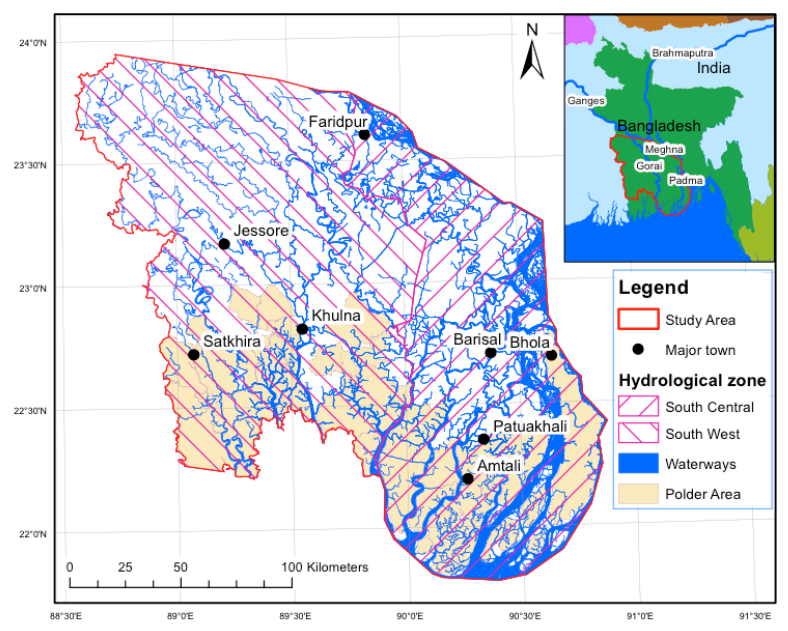

Figure 1. Overview of study area, located in the south-west of Bangladesh. It contains two hydrological zones, south-central and south-west. Most of the land near the coast is enclosed by polders

\section{MATERIAL AND METHODS}

\subsection{Data Sources}

This analysis is based on Landsat 5, 7 and 8 satellite imagery (Level 1T), available for free from http://earthexplorer.usgs.gov. We used the blue, green, red, near infrared (NIR) and both short wave infrared (SWIR) bands, all of which have a resolution of $30 \mathrm{~m}$. The western side of the study area is covered by Landsat path 138 , row 44 and the eastern side is covered by path 137 , rows 44 and 45 . The Landsat 5 and 7 scenes had already been calibrated to surface reflectance by the United States Geological Survey (USGS), while we calibrated the Landsat 8 images to reflectance using the TOA-DOS approach (Chavez, 1996). The NIR band of Landsat 8 has different spectral properties than Landsat 7, which can result in different results when calculating indices. We therefore cross-calibrated Landsat 8 images using Landsat 7 imagery acquired within eight days before and after of the respective scene analyzed.

Data on surface water salinity covering the period from 2002 2012 had been obtained from the Bangladesh Water Development Board. Shape files of the most recent and reliable land elevation and soil salinity classes were collected from the Bangladesh Country Almanac (BCA; 2006) and Soil Resource Development Institute (SRDI; 2000), respectively. The BCA landtype shape file contains inundation classes including Highland, Medium-Highland 1, Medium-Highland 2, MediumLowland, Lowland, and Very Lowland, corresponding to the depths at which flood water is encountered during the monsoon season, as a marker for elevation class, i.e., no consistent floodwater, $<90 \mathrm{~cm}, 90-180 \mathrm{~cm}, 180-275 \mathrm{~cm}$, and more.

\subsection{Cropland Identification}

Cropland was identified using a set of Landsat 5 scenes acquired on either January 21 or 31, 2010. In late January, cropland could be easily separated from forest, since vegetation cover on cropland is generally low at that time. The images were classified into two categories: cropland and "other" which included water, forest, urban areas and land used for aquaculture. In order to avoid potential misclassification due to calibration errors, raw images from the 2 Landsat paths were classified separately. We first created segments with eCognition 9 (Trimble Navigation Ltd., Westminster, CO). Segments are image regions that are more homogeneous within themselves than with nearby regions and represent discrete objects or areas in the image. Each image region then becomes a unit analysis for which a number of attributes, on top of spectral attributes, can be measured and used during the classification (Carleer et al., 2005).

The entire study area measured more than 3 million ha and systematic sampling of ground truth data for the cropland identification would have been a big endeavor. We therefore relied on high resolution background satellite imagery available in ArcGIS 10.1 (ESRI, Redlands, CA) and visually classified more than 250 segments for each of the two classes to create a training data set. High resolution satellite imagery contains much more detailed information than $30 \mathrm{~m}$ Landsat images or segments. Therefore, we chose those segments for training for which the corresponding pixels in the high resolution images showed uniformity. This was eased by the fact that we had to identify just two classes, cropland and non-cropland.

For each segment, the following attributes were used for classification: mean of the digital numbers of bands $1-5$, as well 
as texture (all directions) (Haralick, 1973) and the normalized difference vegetation index (NDVI). Additionally, we calculated the ratio of the NIR band to the visible ones (Equation 1) as follows:

Ratio $_{\text {NIR_Visible }}=\rho_{\text {band } 4} /\left(\rho_{\text {band1 }}+\rho_{\text {band2 }}+\rho_{\text {band3 }}\right)$

Subsequently, the Random Forest Classifier algorithm in WEKA (see Hall, et al., 2009) was used to generate the classification rules. Machine learning algorithms do not depend on normal data distribution assumptions and allow for lumping together distinct classes such as forest, water, urban etc. This reduces the effort needed to create distinct training classes. It also automatically chooses the relevant variables and discards the other ones. Once the classifier had been trained, it was used to classify the remaining segments. Subsequently, a visual quality control of the automatically classified segments was conducted, again using high resolution background imagery as a reference. Wrongly classified segments were manually assigned to the other class.

\subsection{Identification of Waterways and Surface Water Duration}

We used Landsat 5 images acquired on October 26, 2009 and November 8, 2011, coinciding roughly with the end of the monsoon when waterways are at their maximum extent, to identify them. The same methodological approach as for the classification of cropland was used. Some waterways in the study area are ephemeral. We therefore checked for the presences of water in rivers, canals, and creeks using the Automated Water Extraction Index (AWEI; Feyisa, et al., 2014) with atmospherically corrected Landsat 8 images from March 21 and 30, 2014. AWEI sh $_{\text {was }}$ chosen because of its effectiveness in improving water extraction accuracy despite the presence of shadow resulting from trees lining rivers, canals, and water bodies. Using the same threshold as described in the

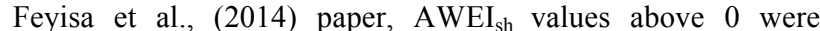
assumed to be water pixels and values below 0 nonwater pixels.

\subsection{Assessment of Land-use Intensity}

Land-use intensity was determined on the base of a total of 44 Landsat 7 and 8 images acquired between 31 December and April 10 of 2011-12, 2012-13, and 2013-14.

Crop productivity mainly depends on the amount of light that is intercepted by a crop during its life cycle (Monteith and Moss, 1977). The enhanced vegetation index (EVI), as described by Huete et al. (2002), is a direct measure of the quantity of light intercepted for photosynthesis. It was successfully used by (Schulthess, et al., 2012) to predict maize yield at the field level in Bangladesh.

We therefore measured the intensity of crop productivity by quantifying the maximum EVI reached by the most widely grown field crops in the study area, including lathyrus, fallow, wheat, mustard, mung bean, Boro rice, and maize. We extracted EVI trends from 10 or more known fields for each of the above crops in each of the 3 years. The use of repetitive and sequential observations is critical to capture maximum EVI because of the heterogeneous nature of agriculture in the study region, resulting in divergent crop phenology both within and across crop species.

Following extraction, EVI values for each of the main crop types were plotted (Fig. 2) as a function of the number of days before or after January 1 , until the $100^{\text {th }}$ day of the year upon which the observation in question was made, corresponding roughly to the first two thirds of the Rabi dry season. We grouped each of the cropland types into three intensity classes, including (1) fallow land (2) low-intensity cropland, comprised of lathyrus, lentil, and mungbean, neither of which are typically fertilized, weeded, or irrigated, and which are broadcasted resulting in sub-optimal crop stands and poor yields (Dalgliesh and Poulton, 2011), and (3) high-intensity cropland, including wheat, Boro rice, maize, and mustard, all of which are more intensively grown with higher levels of fertilizer application, weeding, pest management, and irrigation than in the case of the first two.
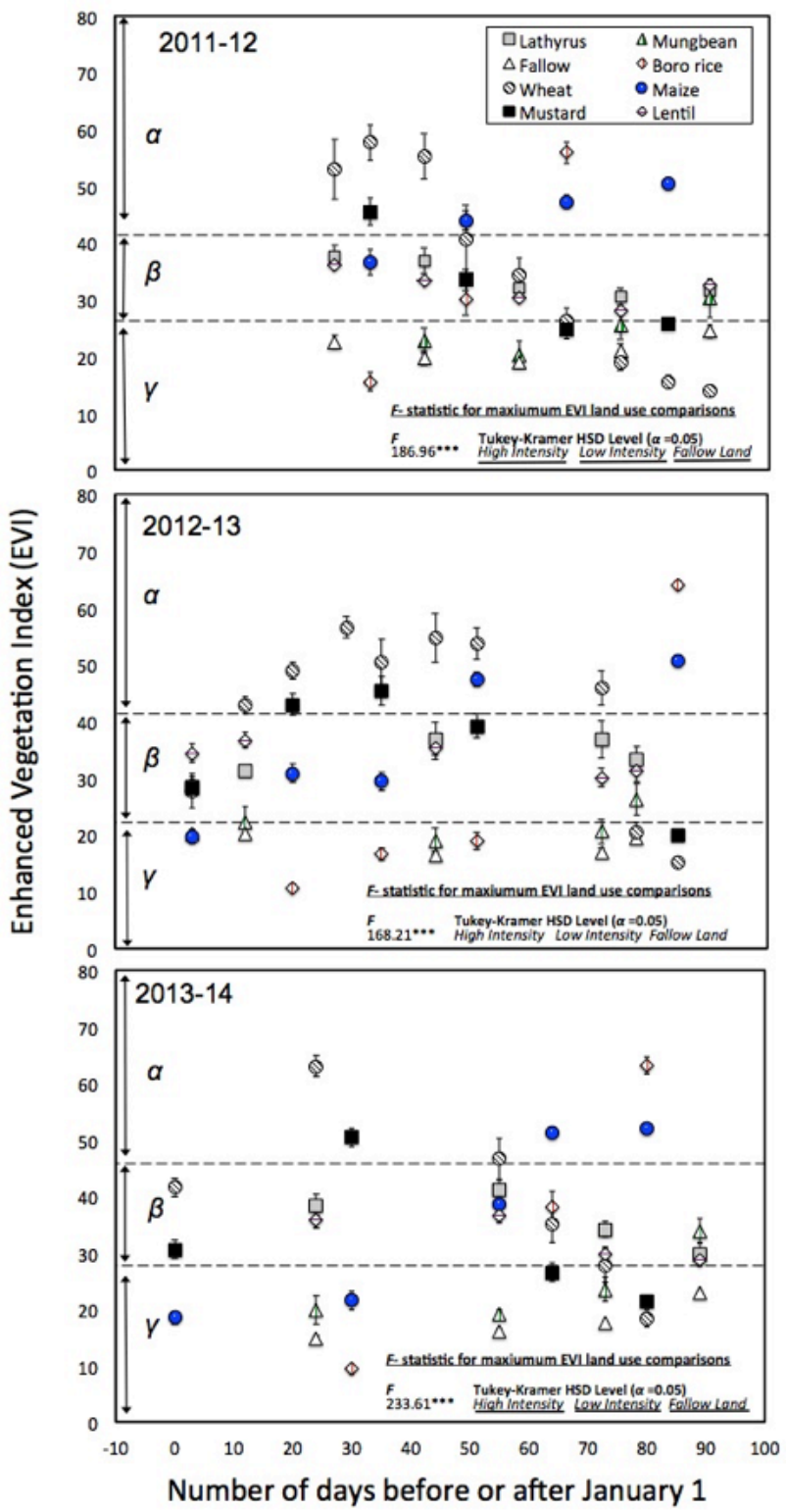

Figure 2. Dynamices of the Enhanced Vegetation Index (EVI) derived from Landsat 7 and 8 images collected over 3 winter seasons in southern Bangladesh for high- $(\alpha$; wheat, maize, mustard, and Boro rice), low-intensity crops ( $\beta$; lathyrus, lentil, and mungbean), and fallow land $(\gamma)$.

After checking for normality and homoscedasticity following Sokal and Rohlf (1995), we subjected data from the date upon which the maximum EVI value (corresponding to maximum 
LAI as a measure of peak productivity) was observed in each class to a one-way ANOVA using JMP 8.0.2 (SAS Institute Inc., Cary, NC) for the 2011-12, 2012-13, and 2013-14 dry seasons. The $F$-test indicated significance $(P<0.001)$ between classes in each of the three seasons analyzed. Separation of means with the Tukey-Kramer's range test at $\alpha=0.05$ showed that the fallow, low-intensity, and high-intensity classes were consistently different and independent in each season.

Because of the significant differences between cropland use intensity classes, we then set thresholds to separate classes to be used for all subsequent EVI analyses. Thresholds were set as the mid-distance point between the lower boundary for the standard deviation of the lowest maximum EVI observation for the highintensity cropland types, and the uppermost boundary of the standard error for the highest EVI observation for the lowintensity crop types. For example, in the 2012-13 season, maize exhibited the lowest maximum EVI within the high-intensity crop use class at 83 days after January 1, while the EVI of lathyrus peaked as the highest observation within the lowintensity class at 27 days. The threshold between high- and lowintensity crop was therefore set as the mid-distance between the lower and upper boundaries for the standard deviations of these observations, respectively. This conservative process was used to distinguish the low-intensity and fallow crop classes for each season studied. The last step in this analysis consisted of the extraction of the maximum EVI value for each pixel of the calibrated Landsat scenes for the entire study area in order to broadly map the three land-use intensity classes for cropland (Fig. 3).

\subsection{Creation of a buffer area around rivers, canals, and creeks}

Since the efficiency of axial flow pumps decreases with lift height, and because they can only push water horizontally without gravity feed within a limited distance (Santos Valle et al., 2014), we created a $400 \mathrm{~m}$ buffer around those waterways in which water was present in late March. The $400 \mathrm{~m}$ width of the buffer was chosen as an empirical value, assumed reachable under most circumstances given feedback from irrigation service providers using the pumps in tandem with flexible hose piping. Intensive agricultural practices can result in sedimentation and nutrient loading of watercourses. Riparian buffers planted with species capable of ameliorating these problems could aid in mitigating the negative effects of crop intensification. We consequently reduced the $400 \mathrm{~m}$ buffer further excluding a $15 \mathrm{~m}$ strip adjacent to rivers and canals from cropping. This resulted in a $385 \mathrm{~m}$ wide buffer, which we deemed potentially suitable for SWI.

\subsection{Interpolation and Temporal Evolution of Surface Water Salinity Dynamics}

Salinity concentrations in the Bangladesh tidal estuary vary in time, with salinity typically increasing as the dry season progresses. This results from the gradual reduction of southward river, canal, and creek water flow following the monsoon season (Brammer, 2013), with important ramifications for irrigation water quality. To account for temporal changes in water salinity, we created four data sets based on the median of the observed data from the second halves of the months January to April over the 11-year period (2002-2012). Each data set was interpolated using Indicator Kriging to create a surface map of salinity. Salinity of river water is being measured at stations on the main rivers only. No data exist for the other water bodies. Hence, kriging was deemed to give a good approximation of the salinity levels of smaller rivers, canals and creeks. Those maps were then classified into three water salinity classes, including 0-2 $\mathrm{dS} \mathrm{m}^{-1}$ (high-quality), 2-4 $\mathrm{dS} \mathrm{m}^{-1}$ (medium-quality), and $>4 \mathrm{dS} \mathrm{m}^{-1}$ (low-quality). Water salinity tolerance varies greatly among crops. While maize is rather sensitive, wheat is much more tolerant. In Australia, a 10\% yield reduction for maize at $1.7 \mathrm{dS} \mathrm{m}^{-1}$ was reported, while for wheat, that threshold was 4.7 $\mathrm{dS} \mathrm{m}^{-1}$ (Evans, 2006).

\subsection{Reclassification and Application of Soil Salinity and Inundation Land Types Shape Files}

The publically available soil salinity map provided by SRDI (2000) comes with various classes, some of them being "mixed", i.e., a polygon may belong predominantly to one class, but may also contain data from another class. To simplify the analysis, we reclassified all data into three classes including $<2$, $2-4$, and $>4 \mathrm{dS} \mathrm{m}^{-1}$ by assigning the highest reported value in each class as the identifier for the new class.

\subsection{Matrix of Land Suitability Based on Soil Surface Water Salinity}

Since either high soil and/or surface water salinity are severe constraints for crop production, we created a matrix as shown in Table 1 as a heuristic tool to simplify the analysis. These thresholds take into account crops that are rather salt intolerant, such as maize. Crop species and even cultivars within a crop species can vary greatly in their ability to withstand soil salinity (Ayers and Westcot, 1989).

\begin{tabular}{|l|c|c|c|c|}
\hline & & \multicolumn{3}{|c|}{ Water Salinity $\left(\mathrm{dS} \mathrm{m}^{-1}\right)$} \\
\hline & $0-2$ & $\begin{array}{c}\text { Highly } \\
\text { suitability }\end{array}$ & $\begin{array}{c}\text { Medium } \\
\text { suitability }\end{array}$ & $\begin{array}{c}\text { Non } \\
\text { suitable }\end{array}$ \\
\hline \multirow{3}{*}{$\begin{array}{l}\text { Soil } \\
\begin{array}{l}\text { Salinity } \\
\left(\mathrm{dS} \mathrm{m}^{-1}\right)\end{array}\end{array}$} & $2-4$ & $\begin{array}{c}\text { Medium } \\
\text { suitability }\end{array}$ & $\begin{array}{c}\text { Low } \\
\text { suitability }\end{array}$ & $\begin{array}{c}\text { Non } \\
\text { suitable }\end{array}$ \\
\cline { 2 - 5 } & $>4$ & $\begin{array}{c}\text { Non } \\
\text { suitable }\end{array}$ & $\begin{array}{c}\text { Non } \\
\text { suitable }\end{array}$ & $\begin{array}{c}\text { Non } \\
\text { suitable }\end{array}$ \\
\hline
\end{tabular}

Table 1. Salinity thresholds of soil and surface water used to determine the suitability classes for agricultural intensification and surface water irrigation.

\subsection{Intersection of the Layers and Suitability Analysis}

Cropland, EVI, surface water salinity, soil salinity, hydrozone, and landtype layers were intersected to assess the suitability of cropland for sustainable intensification. Lastly, a subset of the land within the $385 \mathrm{~m}$ buffer was created. This resulted in a geospatial database that can be queried for extraction of descriptive statistics.

In order to better visualize and summarize the data, we also calculated the percentage of land that could be addressed within grid cells measuring 20 by $20 \mathrm{~km}$. All land that was classified as "Non suitable" due to high salinity levels (Table 1) or belonged to the elevation classes Lowland or Very Low Land was excluded, together with cropland belonging to the class Highintensity. The latter was excluded, since the aim of this paper was to identify areas suitable for intensification.

\section{RESULTS AND DISCUSSION}

The study area covered 3.375 million ha, of which $57 \%$ or 1.926 million ha were identified as cropland. Cropland coverage was 
rather evenly distributed, except for the south-west, where large tracks of land with high surface water and soil salinity levels are being used for aquaculture. The network of waterways is much denser in the south-central than in the south-west hydrozone. Most waterways in the latter hydrozone carry no or relatively small amounts of water in the dry season. Water recharge in that part of Bangladesh has been drastically reduced since the 1976 completion of the Faraka Dam in West Bengal and the plume of saline water in the Khulna - Sathkira region grows steadily in the winter months. Intermediate soil salinity is an issue in the coastal zones of the south, where salinity can range from 2-4 dS $\mathrm{m}-1$, and sometimes can be even higher. Unfortunately, there are no regularly reported surface water salinity data available for the stretch of land south of Amtali to the coastline. Hence, actual water salinity levels for that area are not known and the interpolated data may not be entirely representative for this region.

Land-use intensity levels for all cropland in the study area are summarized in Table 2. Our analysis revealed that in the three years analyzed, fallow land area ranged between 219,000 and 271,000 ha or between 11 and $14 \%$ of the total cropland area. The Ministry of Agriculture and FAO (2012) placed the number for fallow land at 136,000 ha, while the Bangladesh Bureau of Statistics estimated 240,000 ha (2011). Hence, our numbers are largely in agreement with the Bangladesh Bureau of Statistics, but are about double as high as those of the Ministry of Agriculture and FAO. Different definitions of what constitutes fallow land, and slight differences in the land area assessed, may contribute to this discrepancy.

\begin{tabular}{|l|c|c|c|}
\hline Land-use intensity & 2012 & 2013 & 2014 \\
\hline Fallow land & 271,078 & 218,806 & 230,824 \\
\hline Low-intensity & 779,095 & 915,548 & 906,382 \\
\hline High-intensity Total & 876,338 & 790,732 & 789,735 \\
\hline & $1,926,511$ & $1,925,086$ & $1,926,941$ \\
\hline
\end{tabular}

Table 2. Land-use intensity levels of cropland during the Rabi season in the south of Bangladesh in ha. Data were derived based on an analysis of Landsat 7 and 8 images and ground truth data collected by agronomists.

Other estimates of fallow land and land that is suitable for intensification are higher. Using both remotely sensed and administrative data, Rawson et al. (2011) estimated that 800,000 ha of Rabi season fallow or underutilized land suitable to cropping were available in southwestern and southeastern Bangladesh. The Bangladesh Agricultural Development Corporation estimated that 634,000 hectares are regularly fallowed or under low levels of productivity in Khulna and Barisal divisions during the Rabi season (2010), exclusively in the south-west. Taking the average of 2012-2014, we estimate that about 867,000 ha are under low-intensity cropping. Our results are slightly higher than those other estimates.

Noticeable are the intensive production levels of crops grown in the northern half of the study area (Fig. 3). Presumably, most of these fields are planted with Boro rice, wheat or maize, and irrigated with ground water. In the south-central hydrozone, a clear gradient of declining production intensity from the north to the south can be noticed. Ground water in that region has high salinity levels, hence irrigation in the winter months is not commonly practiced. The large tracks of land being cropped at the intermediate and low intensity levels indicate that there is substantial potential to increase food production in the southern part of the south-central hydrozone. Most of that land is actually enclosed by polders. Hence, with an appropriate management of the sluice gates, it might be possible to "harvest" water with low salinity levels for irrigation.
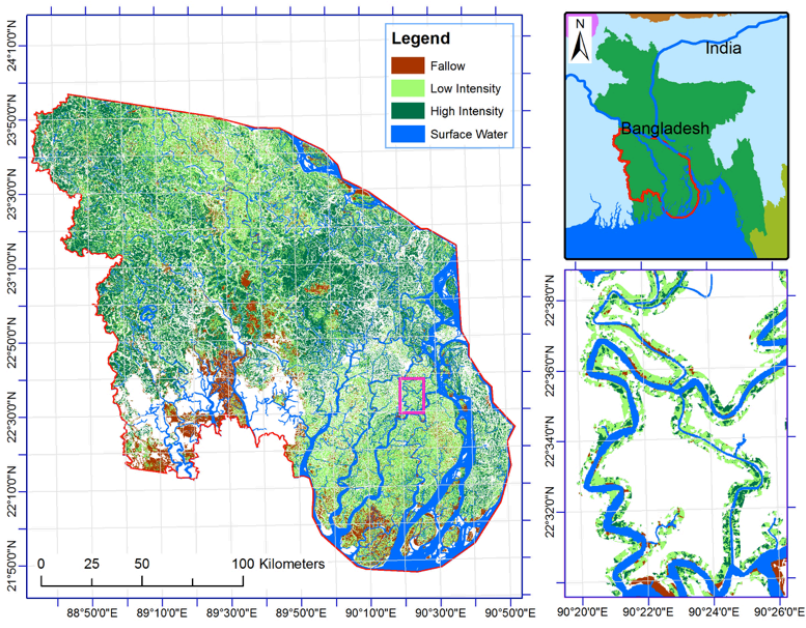

Figure 3: Land use intensity of cropland during the 2014 Rabi season in southern Bangladesh. The analysis was based on a series of Landsat 8 images acquired between December 31, 2013 and late March, 2014. At the lower right, a detailed view of the cropping intensity levels within a $385 \mathrm{~m}$ buffer is given.

Since our main objective was to identify areas suitable for technology targeting with axial flow and similar low-lift, surface water pumps, we created a $385 \mathrm{~m}$ wide buffer within a $15 \mathrm{~m}$ distance adjacent to the waterbodies for which water could be detected with Landsat images. They have a resolution of 30 $\mathrm{m}$, and therefore, a large portion of waterways went undetected. But we might also have included false positives, i.e., land that is adjacent to shallow surface water bodies which are shallow or have a low flow rate and therefore are not a reliable source for irrigation water: We could only detect whether surface water is present or not. When comparing surface water maps of the months of January to April, we noticed a remarkable reduction in the south-west hydrological zone. Hence, due to limited availability of water, it may not be possible to address large tracks of land with SWI in that hydrological zone (see Fig. 1). Hence, the data reported in Table 3 are preliminary indication only of the area of land that might be addressed.

\begin{tabular}{|l|c|c|c|c|}
\hline $\begin{array}{l}\text { Land-use } \\
\text { intensity }\end{array}$ & $\begin{array}{c}\text { Highly } \\
\text { suitable }\end{array}$ & $\begin{array}{c}\text { Medium } \\
\text { suitability }\end{array}$ & $\begin{array}{c}\text { Low } \\
\text { suitability }\end{array}$ & $\begin{array}{c}\text { Non } \\
\text { suitable }\end{array}$ \\
\hline Fallow land & 14,403 & 6,866 & 2,144 & 23,653 \\
\hline Low-intensity & 86,159 & 17,262 & 6,640 & 22,049 \\
\hline High-intensity & 66,562 & 6,524 & 999 & 7,382 \\
\hline Total & 167,124 & 30,652 & 9,783 & 53,084 \\
\hline
\end{tabular}

Table 3: Current land-use intensity of cropland and its suitability for surface water irrigation in the delta region of Bangladesh. Suitability classes are the result of an intersection of soil and water salinity levels as defined in Table 1 . Numbers indicate the area in ha of land that are within a $385 \mathrm{~m}$ buffer adjacent to water bodies on which water was detectable in late March of 2014. Land in the Lowland and Very Lowland classes were excluded from these statistics. 
Figure 4 shows the relative area of land as a percentage of the total area within each of the 20 by $20 \mathrm{~km}$ grid of polygons that potentially could be addressed for sustainable intensification. The most promising region for intensification is in the southeast of the study area. It contains many rivers that are being fed with fresh water from the Padma river even in the dry season, while in the north-west, most water ways tend to dry up in the winter months. However, it is questionable whether the very tip of the south-east area has access to fresh water. As indicated earlier, no measured river salinity data are available for that part. High surface water salinity may pose a severe limitation to intensification in the very south. A more detailed study especially for the South Central hydrological zone, which contains most of the fallow and low-intensity land, is needed to accurately determine the potential for SWI.

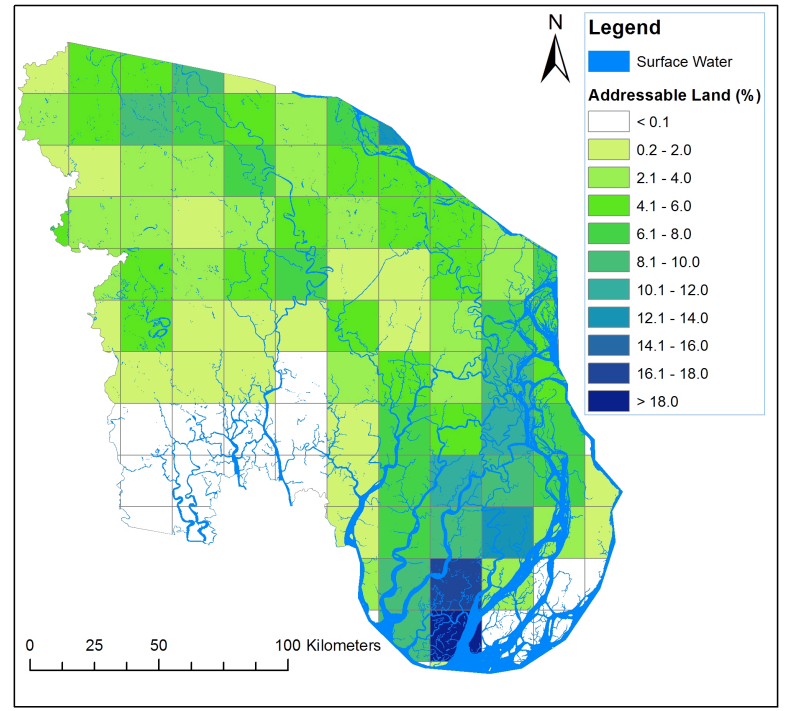

Figure 4: Addressable land suited for sustainable intensification in the delta region of Bangladesh expressed as percentage of total land area in each grid cell. Land belonging to the Nonsuitable class due to high salinity levels or belonging to the Low and Very Low Land classes was excluded.

Almost $80 \%$ of the land within the $385 \mathrm{~m}$ buffer zone next to water ways carrying water in March is in areas where soil and water salinity are below $2 \mathrm{dS} / \mathrm{m}$, whereas only $13 \%$ is in areas that are not suitable. In addition to salinity levels, land elevation is another constraint limiting usability of land. However, we determined that when analyzing the land types of the buffer land, a total of only $3 \%$ of the land is in areas that are either Lowland or Very Low Land. Hence, land elevation is not a major constraint. Based on these constraints, our initial data in this hydrological zone point to approximately 15,300 of fallow and 62,600 hectares of low-intensity land in the South Central zone addressable with quality surface water irrigation, on land which should not be too saline for cropping.

\section{CONCLUSIONS AND RECOMMENDATIONS}

In order to assess the potential of using surface water irrigation in the delta area of Bangladesh, we used a series of Landsat images to analyze current cropping intensities and assess the potential for sustainable intensification through surface water irrigation, considering various constraints such as surface water availability, land elevation, and salinity. In the western hydrological zone, there is only very limited potential for intensification due to a lack of good quality surface water. However, in the southern part of the south-central hydrological zone, there is a lot of land that is currently cropped at lowintensity levels or left fallow. The detailed maps derived in this study will allow for a targeted introduction of axial flow pumps into the delta area of Bangladesh. Field trials will be required to determine optimal irrigation schedules for various crops that can be grown in these areas.

\section{ACKNOWLEDGEMENTS}

This research was conducted under the Cereal Systems Initiative for South Asia - Mechanization and Irrigation (CSISA-MI) project funded by the USAID Mission in Bangladesh. The contents and opinions expressed herein are those of the authors and do not necessarily reflect the views of USAID or the United States Government and shall not be used for advertising or product endorsement purposes. We thank the Soil Resources Development Institute and Bangladesh Water Development Board for access to soil and water quality information.

\section{REFERENCES}

AQUASTAT. 2013. AQUASTAT main country database. Food and Agriculture Organization of the United Nations.

Ayers, R.S. and D.W. Westcot. 1989. Salinity problems. In: FAO, editor Water quality for agriculture. FAO, Rome, Italy. p. $1-32$.

BADC. 2010. Minor irrigation survey report. 2009-2010. Bangladesh Agricultural Development Corporation (BADC), Dhaka.

BBS. 2011. Yearbook of Agricultural Statistics of Bangladesh 2011. Bangladesh Bureau of Statistics (BBS), Dhaka. p. P. 305.

Brammer, H. 2010. After the Bangladesh Flood Action Plan: Looking to the future. Environmental Hazards 9: 118-130.

Brammer, H. 2013. The Physical Geography of Bangladesh University Press Limited, Dhaka.

Dalgliesh, N.P. and P.L. Poulton. 2011. Potential for mungbean in sequence with Rabi-season wheat in southern Bangladesh. In: H. M. Raws, editor Sustainable intensification of Rabi cropping in southern Bangladesh using wheat and mungbean. Australian Centre for International Agricultural Research, Canberra. p. 256.

de Fraiture, C. and D. Wichelns. 2010. Satisfying future water demands for agriculture. Agric. Water Manage. 97: 502-511.

Evans, L. 2006. Salinity tolerance in irrigated crops. NSW Department of Primary Industries, available online at http://www. dpi. nsw. gov. au/agriculture/resources/soils/salinity/crops/tolerance-irrigated.

Feyisa, G.L., H. Meilby, R. Fensholt, R. Simon and S.R. Proud. 2014. Automated Water Extraction Index: A new technique for surface water mapping using Landsat imagery. Remote Sensing of Environment 140: 23-35. 
Garnett, T., M.C. Appleby, A. Balmford, I.J. Bateman, T.G. Benton, P. Bloomer, et al. 2013. Sustainable intensification in agriculture - premises and policies. Science 341: 33-34.

Godfray, H.C.J., J.R. Beddington, I.R. Crute, L. Haddad, D. Lawrence, J.F. Muir, et al. 2010. Food security: the challenge of feeding 9 billion people. Science 327: 812-818.

Godfray, H.C.J., I.R. Crute, L. Haddad, D. Lawrence, J.F. Muir, N. Nisbett, et al. 2010. The future of the global food system. Philosophical transactions of the Royal Society of London. Series B, Biological sciences 365: 2769-2777.

Hall, M., E. Frank, G. Holmes, B. Pfahringer, P. Reutemann and I.H. Witten. 2009. The WEKA data mining software: An Update. SIGKDD Explorations 11: 1.

Haralick, R.M., K. Shanmugam and I. Dinstein. 1973. Textural features for image classification. IEE Transactions on Systems, Man, and Cybernetics SMC-3: 610-621.

Hossain, M.F. 2006. Arsenic contamination in Bangladesh-An overview. Agr. Ecosyst. Environ. 113: 1-16.

Huete, A., K. Didan, T. Miura, E.P. Rodriguez, X. Gao and L.G. Ferreira. 2002. Overview of the radiometric and biophysical performance of the MODIS vegetation indices. Remote Sensing of Environment 83: 195-213.

MOA and FAO. 2012. Master Plan for Agricultural Development in the Southern Region of Bangladesh. Ministry of Agriculture (MoA, Government of Bangladesh) and United Nations Food and Agriculture Organization, Dhaka, Bangladesh. p. 122.

Monteith, J.L., Moss, C.J., 1977. Climate and the efficiency of crop production in Britain [and Discussion]. Philosophical Transactions of the Royal Society B: Biological Sciences 281, 277-294.

Rawson, H.M.E. 2011. Sustainable intensification of Rabi cropping in southern Bangladesh using wheat and mungbean. In: R. H.M., editor ACIAR Technical Reports No. 78 , Australian Centre for International Agricultural Research:. Canberra. p. 256 pp.

Santos Valle, S., Qureshi, A.S., Islam, M.S., Hossain, M.A., Gathala, M.K., Krupnik, T.J., 2014. Axial flow pumps can reduce energy use and costs for low-lift surface water irrigation in Bangladesh. Cereal Systems Initiative for South Asia Mechanization and Irrigation (CSISA-MI) Project, Research Report No. 1. CIMMYT, Dhaka, Bangladesh.

Schulthess, U., J. Timsina, J.M. Herrera and A. McDonald. 2012. Mapping field-scale yield gaps for maize: An example from Bangladesh. Field Crop. Res. 143: 151-156.

Sokal, R.R. and F.J. Rohlf. 1995. Biometry. W.H. Freeman and Company, New York.

SRDI. 2000. Soil Salinity Bangladesh. Soil Resources Development Institute., Dhaka, Bangladesh.

Tilman, D., C. Balzer, J. Hill and B.L. Befort. 2011. Global food demand and the sustainable intensification of agriculture. Proceedings of the National Academy of Sciences of the United States of America 108: 20260-20264.
World Bank. 2010. Updating Poverty Maps of Bangladesh. The World Bank, Bangladesh Bureau of Statistics, World Food Program, Dhaka. p. 17. 